\title{
Preparation, Modification, and Application of Starch Nanocrystals in Nanomaterials: A Review
}

\author{
Ning Lin, ${ }^{1}$ Jin Huang, ${ }^{1,2,3}$ Peter R. Chang, ${ }^{4,5}$ Debbie P. Anderson, ${ }^{4}$ and Jiahui Yu \\ ${ }^{1}$ College of Chemical Engineering, Wuhan University of Technology, 122 Loushi Road, Wuhan 430070, China \\ ${ }^{2}$ Interdisciplinary Science and Technology Institute for Advanced Study, East China Normal University, Shanghai 200062, China \\ ${ }^{3}$ State Key Laboratory of Pulp and Paper Engineering, South China University of Technology, Guangzhou 510640, China \\ ${ }^{4}$ Bioproducts and Bioprocesses National Science Program, Agriculture and Agri-Food Canada, 107 Science Place, \\ Saskatoon, SK, Canada S7N 0X2 \\ ${ }^{5}$ Department of Chemical and Biological Engineering, University of Saskatchewan, Saskatoon, SK, Canada S7N 5A9
}

Correspondence should be addressed to Jin Huang, huangjin@iccas.ac.cn and Peter R. Chang, peter.chang@agr.gc.ca

Received 4 May 2010; Accepted 12 July 2010

Academic Editor: Quanqin Dai

Copyright ( $) 2011$ Ning Lin et al. This is an open access article distributed under the Creative Commons Attribution License, which permits unrestricted use, distribution, and reproduction in any medium, provided the original work is properly cited.

\begin{abstract}
During the past decade, much work has been devoted to the preparation of nanomaterials by blending starch nanocrystals from different sources with various polymer matrices. The following paper summarizes the most up-to-date information available relating to starch nanocrystals and their contribution to research, application, and advancement of diversified nanomaterials. This paper provides an overview of aspects related to starch nanocrystals, including methods for extraction and preparation, chemical modification (with particular emphasis on the modification methods and strategies), reinforcing effects and mechanisms, and applications and prospects.
\end{abstract}

\section{Introduction}

Starch, the major energy reserve of higher plants, is a mixture of two main components: amylose, a linear or slightly branched $(1 \rightarrow 4)$ - $\alpha$-D-glucan, and amylopectin, a highly branched macromolecule consisting of $(1 \rightarrow 4)-\alpha$-Dglucan short chains linked through $\alpha-(1 \rightarrow 6)$ linkages [1]. All starches are biosynthesized as semicrystalline granules containing densely packed polysaccharides and a small amount of water. The conventional model for the inner structure of starch is that it is formed from two regions-crystalline and amorphous lamellae, which together form the crystalline and amorphous growth rings [2]. Figure 1 shows a schematic illustration of the starch granule inner structure and the chemical structure of amylopectin. For the investigation into the intrinsic structure of starch, various measurements were introduced, such as nuclear magnetic resonance (NMR) spectroscopy [1], X-ray microfocus diffraction [3], and small angle $\mathrm{X}$-ray microfocus scattering $[4,5]$, and it was shown that native starch granules possessed an annular structure of alternant crystalline and semicrystalline layers. The growth rings, amorphous (single chain) and ordered (double helix) components [6], are arranged alternately and encircle the point of initiation of the granule, called the hilum (shown in Figure 1). The dominant component of the crystalline region in native starch granules is thought to be amylopectin lamellae $[7,8]$, which pack together to form double helix crystal structure $[9,10]$. In crystallites of starch, parallel stranded double helical structure is found in pairs, and all chains are packed in arrays. The pairing of double helices is identical in both polymorphs and corresponds to the interaction between double helices that has the lowest energy [11].

The crystalline regions of starch granules can be isolated by mild acid hydrolysis using hydrochloric or sulfuric acid. It is believed that at temperatures below the gelatinization temperature acid molecules preferentially attack the amorphous regions of the granule [12] resulting in these regions being more rapidly hydrolyzed than the crystalline regions [13]. The residue after acid hydrolysis contains the starch nanocrystals which have high crystallinity and nanoscale platelet morphology. Angellier-Coussy et al. investigated the molecular structure of waxy maize starch nanocrystals and 
TABle 1: Previous studies concerning the effects of different extraction methods and starch sources on starch nanocrystal size.

\begin{tabular}{|c|c|c|c|c|c|c|}
\hline Starch source & $\begin{array}{l}\text { Concentration of } \\
\text { acid for hydrolysis }\end{array}$ & Temperature & Duration & ${ }^{(a)}$ Structural parameters & Characterization & Ref. \\
\hline \multirow{3}{*}{ Waxy corn starch } & $2.2 \mathrm{~mol} / \mathrm{L} \mathrm{HCl}$ & $36^{\circ} \mathrm{C}$ & 40 days & $\begin{array}{l}\mathrm{L}=20-40 \mathrm{~nm} \\
W=15-30 \mathrm{~nm}\end{array}$ & TEM & {$[21]$} \\
\hline & $3.16 \mathrm{~mol} / \mathrm{L} \mathrm{H}_{2} \mathrm{SO}_{4}$ & $40^{\circ} \mathrm{C}$ & 5 days & $\begin{array}{c}T=5-7 \mathrm{~nm} \\
L=40-60 \mathrm{~nm} \\
W=15-30 \mathrm{~nm}\end{array}$ & TEM & {$[22,24]$} \\
\hline & $3.16 \mathrm{~mol} / \mathrm{L} \mathrm{H}_{2} \mathrm{SO}_{4}$ & $40^{\circ} \mathrm{C}$ & 5 days & $\begin{array}{c}T=6-8 \mathrm{~nm} \\
L=70-100 \mathrm{~nm}\end{array}$ & TEM & {$[30]$} \\
\hline Corn starch & $2.87 \mathrm{~mol} / \mathrm{L} \mathrm{H}_{2} \mathrm{SO}_{4}$ & $45^{\circ} \mathrm{C}$ & 7 days & $L=50 \mathrm{~nm}$ & SEM & {$[33]$} \\
\hline \multirow[t]{2}{*}{ Pea starch } & $3.16 \mathrm{~mol} / \mathrm{L} \mathrm{H}_{2} \mathrm{SO}_{4}$ & $40^{\circ} \mathrm{C}$ & 5 days & $\begin{array}{l}L=60-150 \mathrm{~nm} \\
W=15-30 \mathrm{~nm}\end{array}$ & TEM & {$[19,25]$} \\
\hline & $3.16 \mathrm{~mol} / \mathrm{L} \mathrm{H}_{2} \mathrm{SO}_{4}$ & $40^{\circ} \mathrm{C}$ & 5 days & $L=30-80 \mathrm{~nm}$ & TEM & {$[34]$} \\
\hline \multirow[t]{2}{*}{ Potato starch } & $3.16 \mathrm{~mol} / \mathrm{L} \mathrm{H}_{2} \mathrm{SO}_{4}$ & $40^{\circ} \mathrm{C}$ & 5 days & $\begin{array}{c}L=40-70 \mathrm{~nm} \\
W=10-20 \mathrm{~nm}\end{array}$ & TEM & {$[20]$} \\
\hline & $2.2 \mathrm{~mol} / \mathrm{L} \mathrm{HCl}$ & $35^{\circ} \mathrm{C}$ & 15 days & - & TEM & {$[32]$} \\
\hline
\end{tabular}

${ }^{(a)}$ Data for structural parameters are length $(L)$, width $(W)$, and thickness $(T)$ of starch nanocrystals.

found that there were two major groups of dextrins in the nanocrystals with average degrees of polymerization of 12.2 and 31.7 [14]. The distribution of branched molecules in the two dextrin populations suggests that the starch nanocrystal possesses a regular and largely homogeneous molecular structure. This paper details preparation methods and modification strategies, as well as applications for starch nanocrystals in nanomaterials. The reinforcement mechanism of starch nanocrystals in nanomaterials is recognized and discussed; and the prospects and outlook for chemical modification and application in nanomaterials and biomaterials are presented.

\section{Preparation of Starch Nanocrystals}

In native starch granules, the crystalline and amorphous phases coexist and together form the onion-like structure of the entire starch granule [15]. During the clustering organization process, the amylopectin side chains spiral due to the stacking of nanometric subunits, form the crystalline lamellae and ultimately construct the crystalline region [16]. With acid hydrolysis and/or wet-mashing, regions of low lateral order as well as amorphous phases in the starch granules dissolve, while the highly crystalline water-insoluble lamellae remain. The botanical origin of a starch, namely the type of crystallinity and the relative proportion of amylose and amylopectin, determines the structure and morphology of the starch nanocrystals $[17,18]$. The conditions of hydrolysis during the extraction process (such as the type of acid, acid concentration, temperature, and time) affect the size and yield of starch nanocrystals. Table 1 summarizes the structural characteristics of the crystalline nanolamellae extracted by different acid treatments from various starch sources. Starch nanocrystals derived from various plants have been shown by TEM or SEM to be of various sizes, with the length ranging from 20 to $200 \mathrm{~nm}$, width from 10 to $30 \mathrm{~nm}$, and thickness from 5 to $10 \mathrm{~nm}$. Figures 2(a) and 2(b) show TEM images of starch nanocrystals derived from pea starch [19] and potato starch [20], respectively. Although the starch nanocrystals tend to self-aggregate, the individual and isolated platelets of starch nanocrystals can also be observed.

Through the comparative analysis of data in Table 1, we found that there was little or no variation in the temperature of hydrolysis, which was from $35^{\circ} \mathrm{C}$ to $45^{\circ} \mathrm{C}$. The main reason for low hydrolytic temperature may be to prevent starch gelatinization and destruction of the starch crystalline structure. Of the several factors affecting the hydrolysis process, acid type and duration of hydrolysis are quite distinct, namely, hydrochloric acid $(\mathrm{HCl})$ hydrolysis requires more than 15 days while only 5-7 days are required for sulfuric acid $\left(\mathrm{H}_{2} \mathrm{SO}_{4}\right)$ hydrolysis.

Putaux et al. investigated the optimization of hydrolysis conditions for the extraction of starch nanocrystals with $\mathrm{HCl}$ [21] and $\mathrm{H}_{2} \mathrm{SO}_{4}$ [22] and the effects on morphology and yield. The improved process for extraction of starch nanocrystals by acid hydrolysis followed by preservation is illustrated in Figure 3. Although $\mathrm{HCl}$ hydrolysis produced individual starch nanoplatelets, the long treatment time and low yield inhibit its application as nanofiller in nanomaterials. $\mathrm{H}_{2} \mathrm{SO}_{4}$ hydrolysis was used to prepare starch nanocrystals at a relatively large scale [22]. Response surface methodology was used to optimize the conditions as follows: the initial 


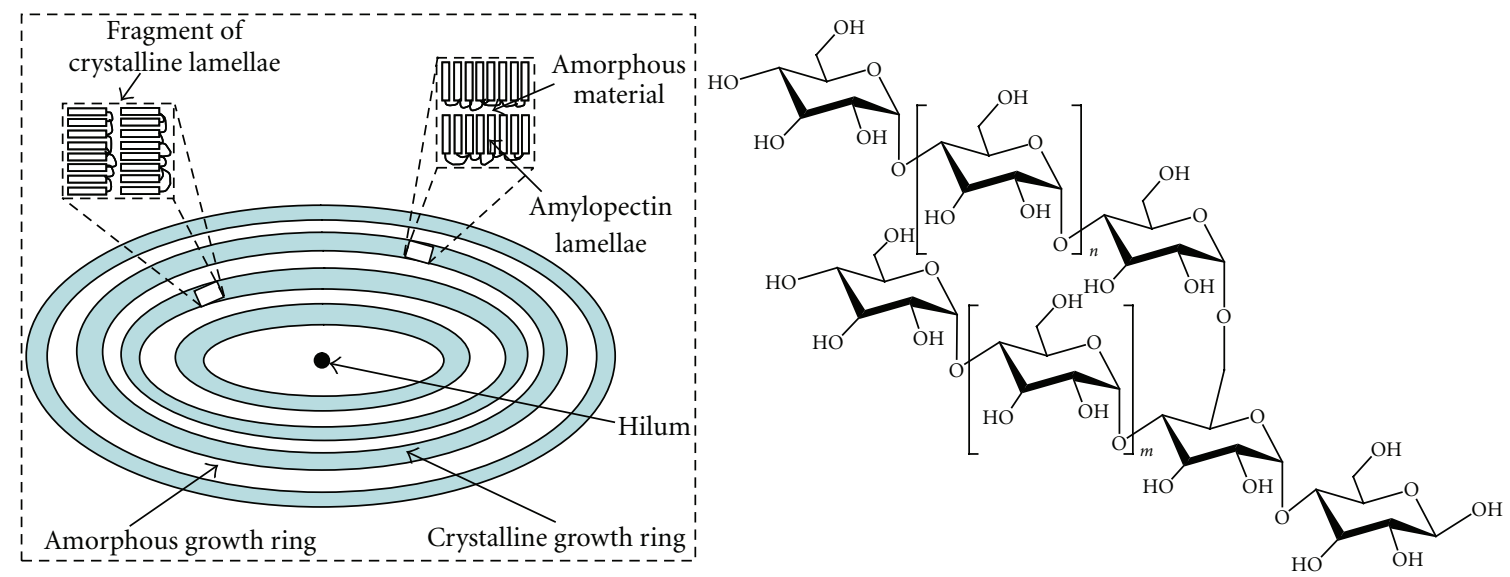

FIGURE 1: Schematic illustration of starch granule structure and chemical structure of amylopectin.

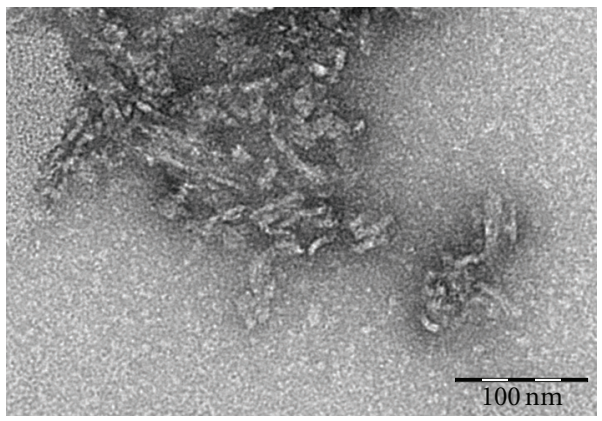

$L=60-150 \mathrm{~nm} W=15-30 \mathrm{~nm}$

(a)

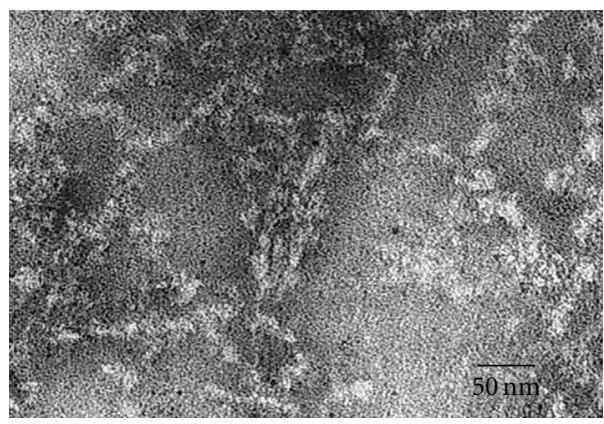

$L=40-70 \mathrm{~nm} W=10-20 \mathrm{~nm}$

(b)

FIGURE 2: TEM images of starch nanocrystals from different sources: pea starch (a) (reproduced from [19] with permission from John Wiley and Sons) and potato starch (b) (reproduced from [20] with permission from Elsevier).

starch with a concentration of $14.69 \%$ in $3.16 \mathrm{~mol} / \mathrm{L} \mathrm{H}_{2} \mathrm{SO}_{4}$ was hydrolyzed at $40^{\circ} \mathrm{C}$ with mechanical stirring at $100 \mathrm{rpm}$ for 5 days. The resultant product had the same shape as that from the ca. 6-week $\mathrm{HCl}$ hydrolysis, but the yield was significantly enhanced (from $0.5 \mathrm{wt} \%$ to $15.7 \mathrm{wt} \%$ ) while the hydrolysis time was shortened to 5 days. It should be pointed out that with the $\mathrm{H}_{2} \mathrm{SO}_{4}$ hydrolysis method, although the sulfate groups on the surface of the starch nanocrystals contribute to dispersion and stability in aqueous solution, they also decrease the thermal stability of the nanocrystals. To solve this problem, a small amount of ammonia $(0.5 \mathrm{wt} \%)$ was added to the $\mathrm{H}_{2} \mathrm{SO}_{4}$ starch nanocrystal suspension before successive centrifugation [23]. This enhanced the thermal stability of the freeze-dried starch nanocrystals and made them suitable for chemical modification. The key element in the preparation of starch nanocrystals is to not destroy the starch crystalline structure while completely removing the amorphous region of starch granules. At the same time, isolating the nanocrystalline lamellae and obtaining the individual, low degree of self-aggregated platelet starch nanocrystals should also be desirably created or maintained.

\section{Chemical Modification of Starch Nanocrystals}

Starch nanocrystals possess a reactive surface covered with hydroxyl groups, which provides the possibility of modification via a chemical reaction strategy. The purpose of chemical modification is to contribute to specific functions and to expand the applications of starch nanocrystals. Angellier et al. estimated the surface hydroxyl group content to be ca. $14 \%$ of the total amount available, for example, only $0.0025 \mathrm{~mol}$ of reactive hydroxyl groups exist in $1.0 \mathrm{~g}$ of freeze-dried starch nanocrystals [26]. This percentage was calculated by constructing a simplified model of a single nanocrystal and counting the surface hydroxyl groups accessible to a water molecule using response surface methodology. There are three strategies for chemical modification of starch nanocrystals: modification by chemical reaction with small molecules, grafting onto polymer chains with coupling agents, and grafting from polymer chains with polymerization of a monomer. Evidence for chemical modification can be found by infrared spectroscopy analysis (FTIR), X-ray photoelectron spectrometry (XPS), and elemental 


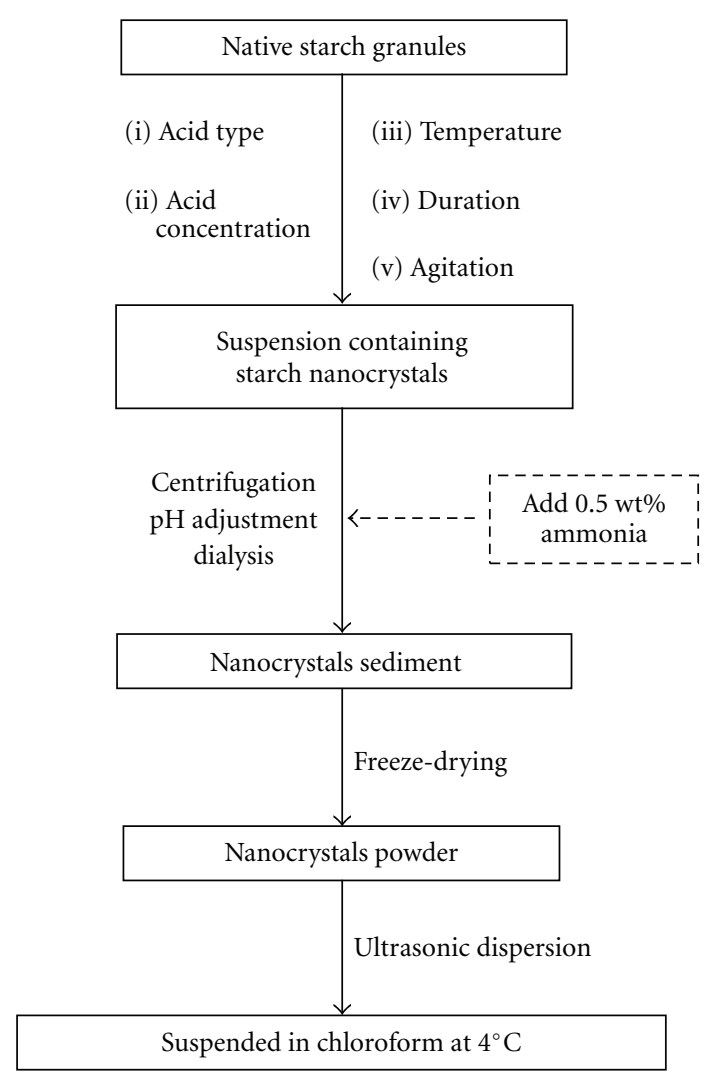

FIgURE 3: Extraction procedure and preservation method for starch nanocrystals.

analysis. Furthermore, the effects of chemical modification of starch nanocrystals, such as changes in morphology and size, solubility or polarity, surface properties, and thermal properties, can be investigated and discussed. It should also be pointed out that any modification strategies must preserve the integrity of the starch nanocrystal's crystalline structure or have a low degree of destruction. The performance of nanomaterials will inevitably be affected because chemical modification transforms the surface characteristics of the starch nanocrystals and hence improves interfacial interactions with the polymer matrix. Strong interfacial adhesion facilitates the transfer of stress and plays a reinforcing role for nanocrystals. In addition, functional modification of the starch nanocrystals, such as grafting to fluorescent molecules, may expand their application in the field of biomedical materials.

3.1. Modification by "Chemical Reaction". The first attempt at modification of starch nanocrystals was a small molecule chemical reaction between hydroxyl groups $(-\mathrm{OH})$ and isocyanate groups $(-\mathrm{NCO})$. Acid hydrolysis of waxy maize starch granules was used to prepare the starch nanocrystals which were then chemically modified on the surface using phenyl isocyanate (PI) in toluene solution [26]. After surface chemical treatment with PI, the platelet-like geometric form of the starch nanocrystals seemed to be preserved, but the size had decreased as compared to unmodified starch fragments. Chemical grafting with PI most probably induced partial solubilization of starch molecules located at the surface of the nanocrystal. In addition, the solubility and polarity of starch nanocrystals were improved. Unmodified starch nanocrystals are not able to migrate into methylene chloride because it has a much higher affinity for water; the PI-modified starch nanocrystals dispersed well in methylene chloride solution, suggesting a lower polar nature of the nanocrystal surface after chemical modification. Analysis of that the contact angle measurement data showed that the contact angle $(\theta)$ values for water changed from $35.3^{\circ}$ to $64.6^{\circ}$, the polar component in the starch nanocrystals decreased from $30.7 \mathrm{~mJ} / \mathrm{m}^{2}$ to $11 \mathrm{~mJ} / \mathrm{m}^{2}$, and surface energy $\left(\gamma_{s}\right)$ decreased from $61.9 \mathrm{~mJ} / \mathrm{m}^{2}$ to $47 \mathrm{~mJ} / \mathrm{m}^{2}$ for the unmodified starch nanocrystals and the PI-modified starch nanocrystals, respectively. These results show that surface chemical modification with isocyanate functions weakened the polarity of the original starch nanocrystals, thereby allowing the use of nonpolar polymers as matrices for composite materials[26].

With the chemical reaction between acetic anhydride and hydroxyl groups, starch nanocrystals can be acetylated and modified by small molecules [27]. The resulting acetylated starch nanocrystals exhibited lower surface energy, increased hydrophobic property, and improved solubility in common organic solvents such as acetone, toluene, $\mathrm{N}, \mathrm{N}$-dimethylformamide, and carbon tetrachloride. The crystalline structure of acetylated starch nanocrystals was also changed from A-style to style V-style. In addition, the platelet-like starch nanocrystals became sphere-shaped after modification and the size increased from original $20-40 \mathrm{~nm}$ to $63-271 \mathrm{~nm}$.

3.2. Modification Based on the "Graft to" Strategy. Although modification by chemical reaction between small molecules and starch nanocrystals improved adhesion between the filler and matrix, the three-dimensional networks of the nanomaterials were partially or totally destroyed, leading to a sharp decrease in mechanical performance of the composites when modified starch nanocrystals (after chemical modification) were used as nanofiller in a polymer matrix. Based on the strategy of "grafting to" polymer chains, novel methods have been put forward and grafting of various polymers (such as poly(ethylene glycol) methyl ether (PEGME) [28], poly(propylene glycol) monobutyl ether (PPGBE) [29], poly(tetrahydrofuran) (PTHF) [29], poly(caprolactone) (PCL) [29], alkenyl succinic anhydride (ASA) [26], and aliphatic chloride [28, 30]) to the surface of starch nanocrystals using different coupling agents has been attempted. The conditions for all of the "graft to" starch nanocrystal modification reactions, including solvent, catalyst, coupling agent, reaction time, and temperature, are summarized in Table 2.

Grafting reactions using the coupling agent 2,4-touene diisocyanate (2,4-TDI) can be accomplished via two synthetic routes due to the different number of end groups in the grafted polymers, namely, the polymers possessing one reactive hydroxyl group and those with two reactive hydroxyl groups. It has been shown that the isocyanate at the 4 positions is 7 times more reactive than that at the 


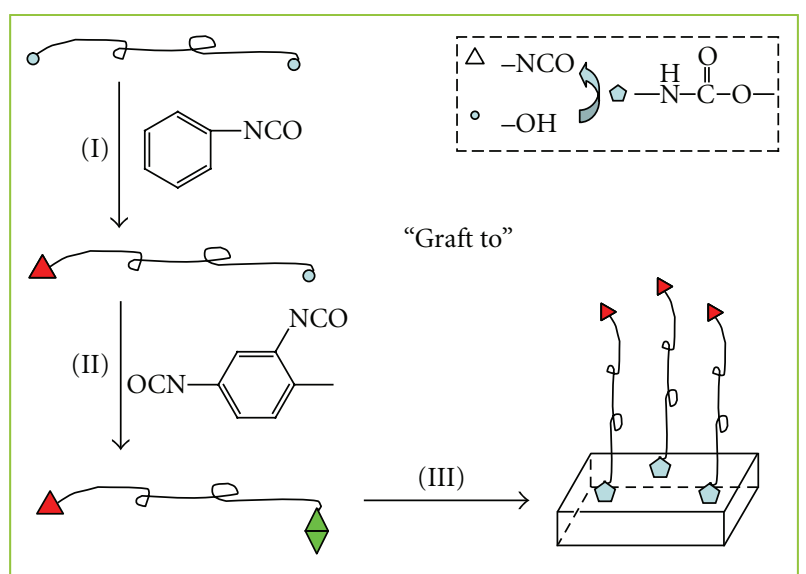

FIGURE 4: Schematic illustration of grafting of polymer chains to the starch nanocrystals based on the "graft to" strategy.

2 positions of 2,4-TDI [31]. Polymers, such as PEGME or PPGBE, with only one end hydroxyl group, are grafted onto the surface of the starch nanocrystals with a two-step process [28]. First, the isocyanate at the 4 position of 2,4TDI reacts with the polymers, and the end hydroxyl group is modified with the isocyanate group. During the second step, the unreacted second isocyanate at the 2 position is reacted with the surface hydroxyl groups of the starch nanocrystals to graft the polymer chains. When there are two end hydroxyl groups on the polymer chains, such as on PTHF and PCL, a capping reaction for one hydroxyl group using phenyl isocyanate (PI) is necessary [29]. As a result, there are three steps for grafting to polymers with two end hydroxyl groups, that is, (i) end capping of one end group, (ii) functionalizing of the other end group, and (iii) polymer grafting onto the starch nanocrystals. A schematic illustration based on the "graft to" procedure for polymer chains with 2,4-TDI as coupling agent is shown in Figure 4. The morphologies of modified starch nanocrystals vary after grafting onto the polymer, resulting from the different relative molecular weights and lengths of the polymer chains. Modification by grafting polymers blocks the hydrogen bond interactions among starch nanocrystals, which may reduce the polarity and surface energy and result in individualization of the nanoplatelets. The comparative analysis of data from total surface energy $(\gamma)$, dispersive surface energy $\left(\gamma^{D}\right)$, and polar surface energy $\left(\gamma^{P}\right)$ indicated that the grafted PEGME chains were expected to be lying flat on the starch surface rather than assembled in a brush-like structure [28]. Grafting of polymer chains on the surface of starch nanocrystal based on the "graft to" strategy is illustrated in Figure 4.

Reaction between the hydroxyl group and the acid chloride group $(-\mathrm{COCl})$ is another method of modification which grafts polymer chains, such as stearoyl chloride [28], octanoyl, nonanoyl, and decanoyl chloride [30], to the starch nanocrystals. Because of the violent esterification reaction between $-\mathrm{OH}$ and $-\mathrm{COCl}$, the modification conditions, such as temperature and $\mathrm{pH}$, should be mild in order to maintain the crystalline structure of the starch nanocrystals, as shown in Table 2. After grafting onto aliphatic polymers, the modified nanocrystals were more individualized and slightly larger in size than their unmodified counterparts. It should be pointed out that when stearate polymer was grafted onto the starch nanocrystal surface, the polymer chains were believed to have taken on a crystalline brush-like structure from the starch surface outward and to reinforce the crystallinity of the nanocrystals. This could be attributed mainly to the high level of surface grafting efficiency and to the covalently linked stearates which crystallize at the starch nanocrystal surface [28]. When the octanoyl, nonanoyl, and decanoyl polymers were grafted, the polarity of the starch nanocrystals decreased and dispersion in organic solvent improved. As for the stearate modified starch nanocrystals, it is interesting to note that the polarity of the starch-stearate surface disappeared, which is attributed to efficient surface coverage by the stearate aliphatic chain ends. Grafting to alkyl polymer chains also improved the thermal properties. For example, grafting to stearate chains resulted in an increase of more than $100^{\circ} \mathrm{C}$ in the degradation temperature of starch because of the protective crystalline layer formed by the oxygen-poor stearate surface [28]. Similarly, after grafting to octanoyl, nonanoyl, and decanoyl polymers, the low amount of hydroxyl groups remaining after acylation caused the modified starch nanocrystals to have greater thermal stability [30].

In conclusion, the described "graft to" surface modifications clearly change characteristics of the starch nanocrystals, such as morphology, size, polarity, dispersion in aqueous or organic solvents, surface properties, and thermal properties, while keeping the crystalline integrity. The ultimate purpose of chemical modification is to achieve a reinforcing effect in nanomaterials, which would allow the use of nonpolar polymers as matrices for nanocomposite materials, and stimulate the functional application of starch nanocrystals.

3.3. Modification Based on the "Graft from" Strategy. Although various polymers have been used in attempts to modify the surface of starch nanocrystals based on the "graft to" strategy, there are still some shortcomings, such as low controllability and grafting efficiency, as well as difficulty in grafting long-chain polymers. To solve these problems, a novel "graft from" strategy has been proposed in which polymerization of monomers and chain propagation of polymers are induced, and ultimately the polymer chains are coupled with the starch nanocrystals. Using the "graft from" strategy, together with ring-opening polymerization (ROP) for poly (E-caprolactone) (PCL) $[23,25,32]$ and free radical polymerization (FRP) for polystyrene (PS) [33], different polymers have been grafted from the surface of starch nanocrystals. Figure 5 shows a schematic illustration of grafting polymer chains onto a starch nanocrystal based on the "graft from" strategy. With this strategy, a higher grafting density can be realized; and through the selection and control of the grafting polymer chains' length and type, for example, polar or nonpolar grafting chains, the properties of starch nanocrystals can be regulated. The grafted chains will improve the compatibility between nanocrystals and matrix 
TABLE 2: Reaction conditions for the "graft to" strategy for starch nanocrystal modification reactions.

\begin{tabular}{|c|c|c|c|c|c|c|c|}
\hline Graft polymers & Coupling agents & Solvent & Catalyst & $\begin{array}{l}{ }^{(a)} \text { Reaction } \\
\text { temperature }\end{array}$ & (a) Reaction time & ${ }^{\text {(b) }}$ Characterization & Ref. \\
\hline PEGME $_{550}$ & 2,4-TDI & Toluene & DTD & $70^{\circ} \mathrm{C}$ & 7 days & $\begin{array}{l}\text { BET, FTIR, XPS, } \\
\text { TEM, CAM }\end{array}$ & [28] \\
\hline $\mathrm{PPGBE}_{4000}$ & 2,4-TDI & Toluene & TEA & $70-80^{\circ} \mathrm{C}$ & 7 days & $\begin{array}{l}\text { FTIR, XPS, EA, } \\
\text { TEM, CAM }\end{array}$ & [29] \\
\hline $\mathrm{PTHF}_{1400}$ & $\begin{array}{l}\text { 2,4-TDI (PI capping } \\
\text { first) }\end{array}$ & Toluene & TEA & $70-80^{\circ} \mathrm{C}$ & 7 days & $\begin{array}{l}\text { FTIR, XPS, EA, } \\
\text { TEM, CAM }\end{array}$ & [29] \\
\hline $\begin{array}{l}\mathrm{PCL}_{10000} \\
\mathrm{PCL}_{42500} \\
\end{array}$ & $\begin{array}{l}\text { 2,4-TDI (PI capping } \\
\text { first) }\end{array}$ & Toluene & TEA & $70-80^{\circ} \mathrm{C}$ & 7 days & $\begin{array}{l}\text { FTIR, XPS, EA, } \\
\text { TEM, CAM }\end{array}$ & [29] \\
\hline Stearate polymer & stearic acid chloride & $\begin{array}{l}\text { Methyl ethyl } \\
\text { ketone }\end{array}$ & TEA & $60^{\circ} \mathrm{C}$ & 4 days & $\begin{array}{l}\text { BET, FTIR, XPS, } \\
\text { TEM, CAM }\end{array}$ & {$[28]$} \\
\hline \multicolumn{2}{|c|}{ (c) Aliphatic polymers thionyl chloride } & Water & - & $20^{\circ} \mathrm{C}$ & $20 \mathrm{~min}$ & FTIR, EA, TEM & [30] \\
\hline $\mathrm{ASA}_{350}$ & - & Toluene & 4-DAP & $70^{\circ} \mathrm{C}$ & 7 days & $\begin{array}{l}\text { FTIR, XPS, TEM, } \\
\text { CAM }\end{array}$ & {$[26]$} \\
\hline
\end{tabular}

TEA: triethylamine, DTD: dibutyltin dilaurate, 2,4-TDI: 2,4-toluene diisocyanate, PI: phenyl isocyanate, ASA: alkenyl succinic anhydride, 4-DAP: dimethyl amino pyridine, BET: Brunauer-Emmett-Teller, FTIR: Fourier transform infrared, EA: elemental analysis, TEM: transmission electron microscopy, XPS: Xray photoelectron spectrometry, and CAM: contact angle measurement. (a)Reaction temperature and time listed in the table are assigned to the temperature and time of modified polymer chains grafted onto starch nanocrystals. (b) Characterization listed in the table refers to the measurements for proving the success of modification. (c) Aliphatic polymers include octanoic (C8), nonanoic (C9) and decanoic (C10) polymers.

and facilitate the transformation of structures and properties of nanocomposites filled with starch nanocrystals.

Under the different conditions of microwave assisted and thermal ring-opening polymerization, the surfaces of starch nanocrystals were functionalized by grafting with polycaprolactone (PCL) chains. Figure 6 shows a TEM image of PCLmodified starch nanocrystals and the reaction mechanism of ring-opening polymerization based on the "graft from" strategy. As shown in the image, after microwave assisted chemical modification most modified nanocrystals show a plateletlike structure of less than $100 \mathrm{~nm}$, suggesting that the process of grafting PCL chains facilitates the dispersion of nanocrystals $[23,25]$. In another work, the method of bulk polymerization was used to graft PCL polymer chains to starch nanocrystals [32]. With the analysis of Differential Scanning Calorimetry (DSC) measurements, it seems that chemical modification caused the decomposition of grafting copolymer in the broader range of temperature but the crystalline structure and morphology of nanocrystals are unaltered.

Another method of chemical modification of starch nanocrystals is free radical polymerization on the starch nanocrystal surface. An amphiphilic starch nanocrystal copolymer was prepared by graft copolymerization of starch nanocrystals with styrene [33]. During the hydrolysis process, the amorphous region of the starch was hydrolyzed and removed, and $50 \mathrm{~nm}$ particles were obtained as starch nanocrystals. After grafting the hydrophobic polystyrene chains, the modified starch nanocrystals transformed as the amphiphilic nanoparticles, which exhibited the size of around $80-100 \mathrm{~nm}$ spheral morphology. The amphiphilic starch nanocrystals dispersed well in both polar and nonpolar solvents. The excellent amphiphilic characteristic was attributed to the different conformation variations of the hydrophobic polystyrene side chains and to the hydrophilic starch backbone when in polar or nonpolar solvent.

\section{Application of Starch Nanocrystals}

4.1. Natural Polymers as Matrix. With natural rubber latex as the matrix and an aqueous suspension of waxy maize starch nanocrystals as the reinforcing phase, starch nanocrystals have been introduced into natural rubber for the preparation of nanocomposites [35]. The basic procedure was as follows: (i) mixing an aqueous suspension of starch nanocrystals and natural rubber latex, (ii) vacuum degassing, (iii) water evaporation, first at $40^{\circ} \mathrm{C}$ under atmospheric conditions for $6-8 \mathrm{~h}$ and then at $60^{\circ} \mathrm{C}$ under vacuum for $2 \mathrm{~h}$, and (iv) film formation. The starch nanocrystal content in the resultant composites ranged from $2 \mathrm{wt} \%$ to $50 \mathrm{wt} \%$. The performance of the nanocomposites and various structural properties (such as morphology, crystallinity, swelling behavior, barrier properties to water vapor and oxygen, thermal properties, and mechanical properties) were investigated. Starch nanocrystal filler was evenly distributed within the natural rubber matrix, which is very important for producing good mechanical properties. Meanwhile, preparation of the nanocomposites did not destroy the crystalline structure of the starch nanocrystals, as verified by wide-angle X-ray diffraction analysis. It is interesting to note that the swelling of nanocomposites in toluene decreased and the swelling in water increased with the introduction of starch nanocrystals to the natural rubber. It was assumed that these phenomena were attributed to the formation of the starch nanocrystal three-dimensional network through hydrogen linkages between starch nanoparticle clusters and also to favorable interactions between the matrix and filler. It should be noted 


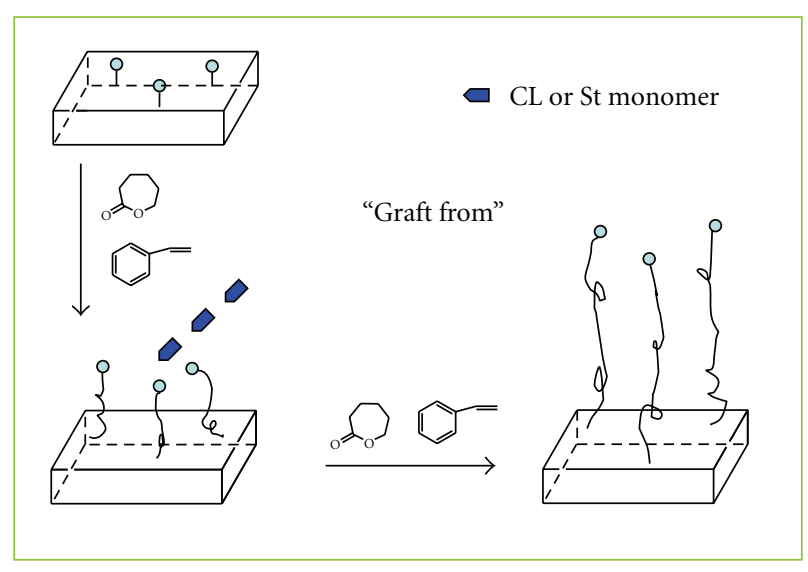

FIGURE 5: Schematic illustration of grafting polymer chains on a starch nanocrystal based on the "graft from" strategy.

that the addition of starch nanocrystals induced a decrease in permeability to both water vapor and oxygen of natural rubber-based nanocomposites. Water Vapor Transmission Rate (WVTR) gradually decreased from $0.078 \mathrm{~g} /(\mathrm{m} \cdot$ day) for neat natural rubber composite to $0.043 \mathrm{~g} /(\mathrm{m} \cdot$ day) for nanocomposite with a starch nanocrystal content of $20 \mathrm{wt} \%$. At the same time, the higher the starch content was, the greater the decrease in oxygen permeability, that is, $17.9 \%$ for the composite with $10 \mathrm{wt} \%$ starch nanocrystals, $20.3 \%$ for the composite with $20 \mathrm{wt} \%$ starch nanocrystals, and $47 \%$ for the composite with $30 \mathrm{wt} \%$ starch nanocrystals [35]. It is believed that the platelet-like low permeability structure of starch nanocrystals stands in the way of the water vapor or oxygen molecules, increasing the tortuosity of the diffusion path, and ultimately affecting the barrier properties of the natural rubber based composites. The mechanical properties of composites also improved with the introduction of starch nanocrystals. For example, at room temperature the relaxed modulus of nanocomposites containing 10, 20, and $30 \mathrm{wt} \%$ filler was about 10, 75, and 200 times higher, respectively, than the neat natural rubber material. It was shown that with a content of up to $20 \mathrm{wt} \%$, this new filler presented the advantage of effectively reinforcing the natural rubber without significantly decreasing the elongation at break $\left(\varepsilon_{b \text {,true }}\right)$ of the material. For example, $\varepsilon_{b \text {,true }}$ decreased slightly from $303 \%$ to $277 \%$ whereas the strength $\left(\sigma_{b, \text { true }}\right)$ increased sharply from $77.1 \mathrm{MPa}$ to $229.5 \mathrm{MPa}$ (the former values are for the neat natural rubber material and the latter values are for the nanocomposite with $20 \mathrm{wt} \%$ starch nanocrystal filler) $[24,36]$. In view of the positive effects of starch nanoparticles on barrier and mechanical properties of the natural rubber matrix, Novamont (Novara, Italy), working in partnership with Goodyear Tire and Rubber (America), has recently developed tires using nanoparticles derived from corn starch, partially replacing the conventional carbon black and silica used in making tires. This patented innovation, called BioTred, presents environmental advantages but also reduces the rolling resistance of tires [37]. Starch nanocrystals were also proved to have the potential as the substituted nanofiller for natural rubber [35].
Waxy maize starch nanocrystals have also been used as a reinforcing agent in a waxy maize starch matrix with various plasticizers. Contrary to natural rubber, starch is a thermoplastic and polar matrix, and when starch nanocrystals are used as the nanofillers in starch-based materials the chemical structures of the matrix and filler are similar. These particulars promote good miscibility and strong interfacial adhesion between the starch nanocrystal filler and the starch matrix. Angellier et al. and Viguié et al. investigated the effects of plasticizer content, starch nanocrystal filler content, and aging on the reinforcing properties of starch-based nanocomposites [38, 39]. When a glycerol content of $25 \mathrm{wt} \%$ was selected to plasticize the materials, the mechanical properties of the starch-based nanocomposites reinforced with starch nanocrystals were clearly higher than those of the unfilled matrix, even after aging of the material [38]. This reinforcing effect was attributed to the establishment of strong interactions not only between the starch nanocrystals but also between the filler and the matrix and was probably also due to crystallization that may have occurred at the filler/matrix interface. At the same time, the increase in $T_{g}$ for starch-based materials, resulting from hydrogen bonding between the filler and matrix restricting the molecular mobility of the matrix amylopectin segments, slowed retrogradation of the starch matrix considerably. The starchbased nanocomposites plasticized with sorbitol exhibited a similar reinforcing effect on mechanical and thermal properties of starch nanocrystals [39]. In addition, it should be noted that retrogradation of the starch matrix, which occurred in both sorbitol- and amylopectin-rich domains of the unfilled matrix, was restricted to amylopectin-rich domains in the starch nanocrystal reinforced matrix, which may be attributed to the occurrence of the transcrystallization phenomenon.

Alkenyl succinic anhydride (ASA) is a polymer with an acid anhydride group that can be chemically reacted with hydroxyl groups on the starch nanocrystal surface by using 4-dimethyl amino pyridine as the catalyst [26]. Because the modified starch nanocrystals are surrounded by ASA molecules, they exhibit a flocky conglomeration morphology, not the original platelet shape. Surface chemical modification with anhydride functions enhances the nonpolar nature of starch nanocrystals and also preserves the initial crystalline structure.

Glycerol plasticization and compression molding was used to incorporate pea starch nanocrystals into a soy protein isolate (SPI) matrix to produce a class of fully biodegradable nanocomposites [19]. The rigid starch nanocrystals showed a prominent reinforcing function that was dependent upon uniform dispersion and strong interfacial interaction between the filler and matrix. The reinforcing effect was however restricted by size expansion of the starch nanocrystal domains. As a result, in contrast to neat soy protein material, nanocomposite with a low starch nanocrystal loading level $(2 \mathrm{wt} \%)$ showed the highest strength and Young's modulus, which were enhanced by ca. $50 \%$ and $200 \%$, respectively. With an increase in starch nanocrystal content, the number and size of starch nanocrystal domains increased, thus lowering the filler's effective active surface 

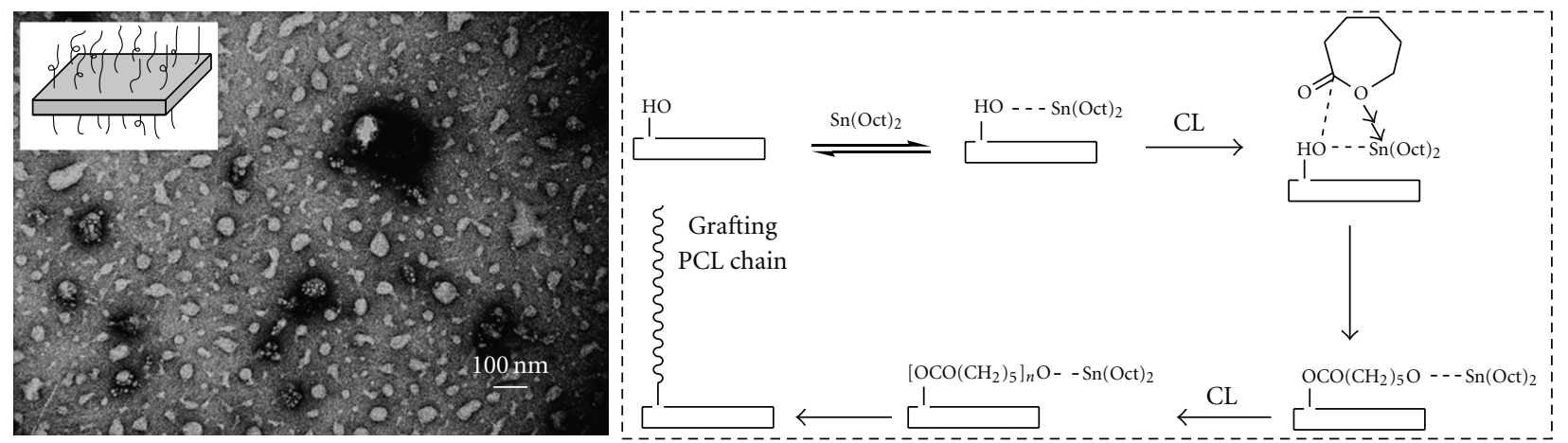

Figure 6: TEM image of grafted PCL polymer on starch nanocrystals (reproduced from [25] with permission from Wiley-VCH Verlag $\mathrm{GmbH} \& \mathrm{Co} . \mathrm{KGaA}$ ); and reaction mechanism of ring-opening polymerization based on the "graft from" strategy (reproduced from [23] with permission from John Wiley and Sons).

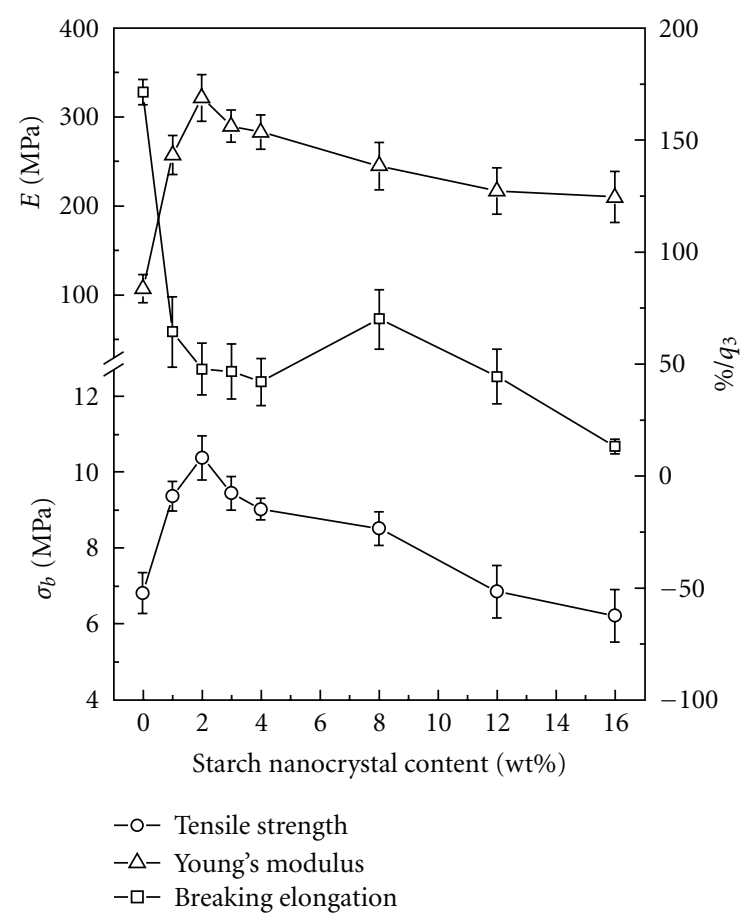

FIGURE 7: Effect of starch nanocrystal content on mechanical performance of soy protein-based nanocomposites (Reproduced from [19] with permission from John Wiley and Sons).

area available for interaction with the soy protein matrix. The increased filler level also destroyed the ordered structure of the soy protein matrix, causing a gradual decrease in strength and Young's modulus. In addition, although the starch nanocrystals introduced were relatively hydrophilic, the water uptake of the nanocomposites showed no obvious change [19]. The effect of starch nanocrystal content on the mechanical performance of soy protein-based nanocomposites is shown in Figure 7. In another case, sorbitolplasticized pullulan nanocomposites filled with waxy maize starch nanocrystals showed substantial improvement in mechanical and water resistance properties as compared with the unfilled material [40]. The water barrier properties of the nanocomposites were particularly enhanced with a high filler content (20 wt $\%)$, and the thermal stability of pullulan-based material was also improved.

4.2. Synthetic Polymers as Matrix. Different from natural polymers, synthetic polymers are versatile materials with many industrial applications because of their excellent physical properties and chemical resistance. The shortcomings of synthetic polymers are also numerous, including the high cost, non-biodegradability, non-biocompatibility, and poor mechanical or thermal performance of some polymers. The introduction of starch nanocrystals into synthetic polymer matrices should ameliorate these problems to some degree. Pea starch nanocrystals were blended with poly(vinyl alcohol) (PVA) to produce nanocomposites [34]. The nanocomposites containing starch nanocrystal at levels of 5 and $10 \mathrm{wt} \%$ exhibited improved physical properties, namely, higher light transmittance, tensile strength, elongation at break, and lower moisture uptake, as compared with the neat PVA material. In another work, waxy maize starch nanocrystals were introduced as filler into an acrylic polymer matrix, namely, poly(styrene-co-butyl acrylate) (poly(S-co$\mathrm{BuA})$ ) [41]. Dynamic mechanical analysis (DMA) showed that the mechanical properties of these composites were substantially improved by increasing the amount of filler. With the high loaded level (ranging from 0 to $60 \mathrm{wt} \%$ ), potato microcrystalline starch was also used to reinforce the thermoplastic poly(S-co-BuA) matrix, which brought a great reinforcing effect, especially at temperatures higher than the $T_{g}$ of the synthetic matrix [42].

The introduction of potato starch nanocrystals into waterborne polyurethane (WPU) [20] led to nanocomposites with enhanced tensile strength, Young's modulus, and elongation. With a starch nanocrystal content of only $2 \mathrm{wt} \%$, the strength and elongation of the composite were enhanced by ca. 1.7- and 2.6-fold, respectively, over those of the neat waterborne polyurethane material. The improvements in mechanical performance are mainly attributed to the enduring stress of rigid starch nanocrystals and to the 
stress transfer mediated by the strong interfacial interaction between the starch nanocrystal surface and the waterborne polyurethane matrix, as well as to the relatively uniform dispersion of the starch nanocrystals. When the loading level of starch nanocrystals was relatively high ( $>8 \mathrm{wt} \%)$, the size and amount of the starch nanocrystal inevitably expanded due to the strong tendency for self-aggregation of starch nanocrystals. This resulted in a decrease in the effective active surface of the filler phase and weakened the interfacial adhesion, the essential association between filler phase and matrix. At the same time, excess breakage of conventional organization and interaction in the waterborne polyurethane matrix, as well as the formation of a microphase separation in the composites, ultimately inhibits further enhancement of mechanical performance [20]. In another work, waxy maize starch nanocrystals were introduced as the reinforcing phase in the modification of waterborne polyurethane, which exhibited improvements in strength and thermal stability of the materials [43]. Based on a "graft from" strategy, the surface of starch nanocrystals was functionalized by grafting with polycaprolactone (PCL) chains using microwave-assisted ring-opening polymerization [23]. The modified nanocrystals were then loaded into the waterborne polyurethane matrix. The nanocomposite containing the lowest loading level of $5 \mathrm{wt} \%$ grafted copolymers showed the maximum tensile strength and elongation, which were also higher than those of neat waterborne polyurethane. The grafted PCL chains used for surface functionality of starch nanocrystals were of the same origin as the soft segment $\left(\mathrm{PCL}_{2000}\right)$ of the waterborne polyurethane matrix, which facilitated the uniform dispersal of the nanoscale fillers and hence improved the miscibility between filler and matrix. As the point of stress concentration, the starch nanocrystals performed the reinforcement function fully, resulting in enhanced strength. At the same time, increasing entanglements mediated with grafted PCL chains facilitated the increase in elongation [23].

Chemically modified starch nanocrystals have also been used as reinforcing filler for synthetic and biodegradable polyester matrices, such as poly(lactic acid) (PLA) and polycaprolactone (PCL). In the case of a "graft from" starch nanocrystal-graft-poly ( $\varepsilon$-caprolactone) (StN-g-PCL) filled into a poly(lactic acid) matrix, PCL polymer chains were grafted onto the surface of starch nanocrystals via microwave-assisted ring-opening polymerization [25]. The resultant modified nanocrystals were then incorporated into a poly(lactic acid) matrix by solution mixing, and the film was then solidified to produce fully biodegradable nanocomposites. The addition of grafted PCL starch nanocrystals resulted in a pronounced enhancement of elongation together with a decrease in Young's modulus.

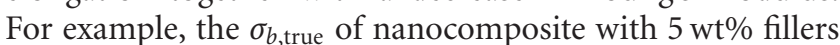
was ca. 10-fold over that of neat PLA material, as shown in Figure $8(\mathrm{a})$. This was attributed to the introduction of the rubbery PCL component which provided flexibility to the nanocomposite and contributed to the increase in elongation. An increase in modified nanocrystal content, however, led to nanofiller self-aggregation and microphase separation between filler and matrix, resulting in a decrease

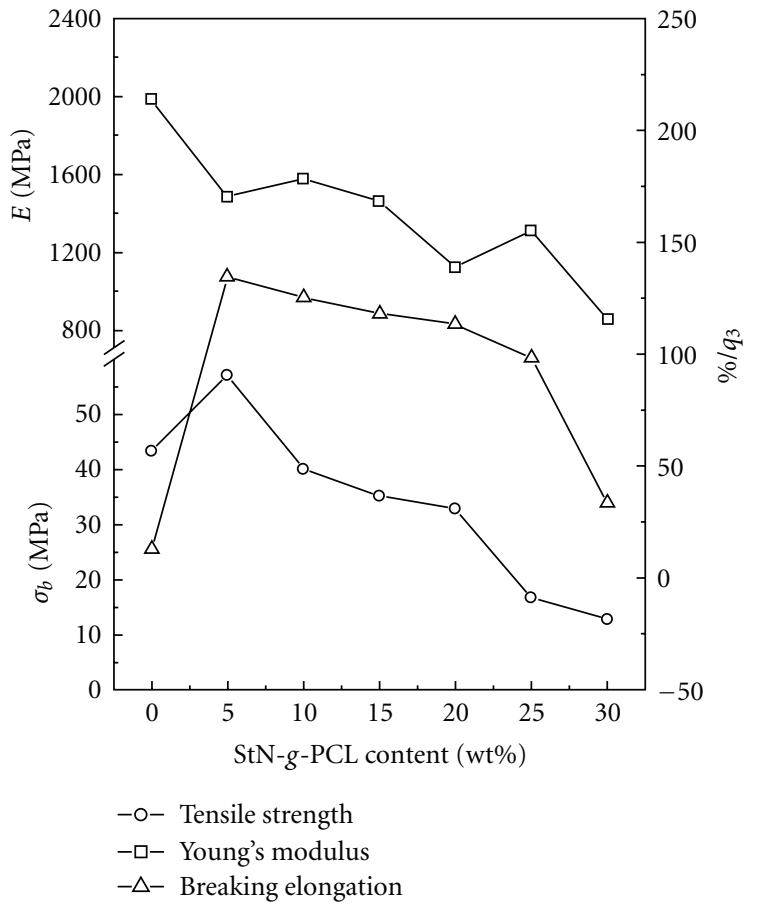

(a)

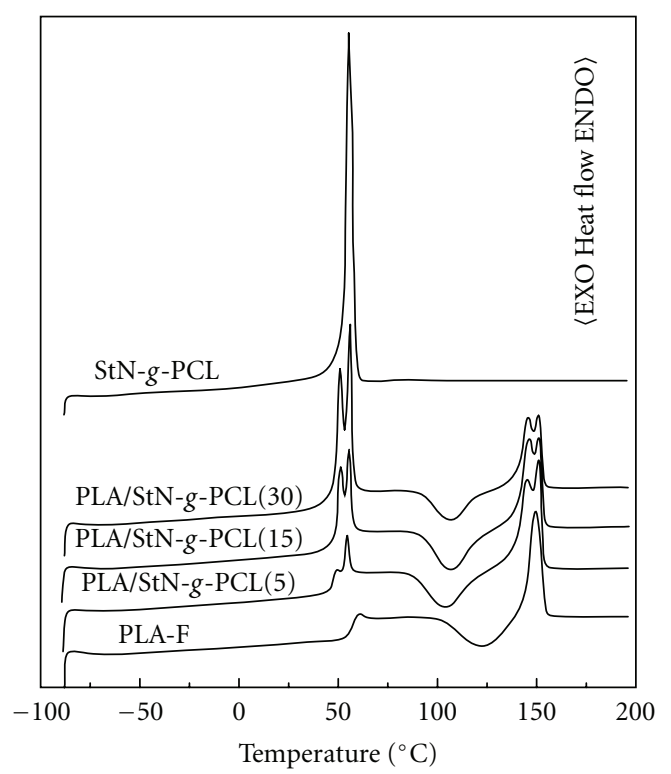

(b)

Figure 8: Effects of PCL content in copolymer starch nanocrystal grafting on mechanical performance of PLA-based nanocomposites (a) and DSC thermograms of nanocomposites with various grafted copolymer contents (b) (Reproduced from [25] with permission from Wiley-VCH Verlag GmbH \& Co. KGaA).

in nanocomposite strength and elongation. The introduction of modified starch nanocrystals into the PLA matrix also affected the thermal properties of the composites. DSC thermograms of nanocomposites with various filler contents are shown in Figure 8(b). The glass transition temperature $\left(T_{g \text {,mid }}\right)$ assigned to PLA shifted from $57.7^{\circ} \mathrm{C}$ to $47.8^{\circ} \mathrm{C}$ 
for nanocomposite with $5 \mathrm{wt} \%$ grafted copolymer filler and was absent in nanocomposites with higher loading levels $(>15 \mathrm{wt} \%)$. This was attributed to an improvement in freedom of motion of the PLA matrix during melting of the grafted PCL component. In addition, the frozen motion of glassy PLA segments in the interfacial layer (composed of PCL and PLA chains) results in a slight shift to a lower melting temperature $\left(T_{m}\right)$ for PCL [25].

The "graft to" method links polycaprolactone (PCL) chains of various molecular weights $\left(\mathrm{PCL}_{10000}\right.$ and $\left.\mathrm{PCL}_{42500}\right)$ covalently onto the surface of starch nanocrystals by an isocyanate-mediated reaction. Both unmodified and modified nanocrystals were used to prepare highly filled nanocomposites using a casting/evaporation method with a PCL matrix [44]. The addition of PCL-grafted waxy maize starch nanocrystals resulted in a continuous increase in the tensile modulus as verified by DMA experiments. Disappointingly, there was also a gradual decrease in both the strength and elongation at break when PCL-modified starch nanocrystal filler was added, as compared to the neat PCL material. Although grafted chains of the same component as the matrix promote better filler dispersion within the polymeric matrix, low grafting efficiency, resulting from chain entanglements between grafted chains and PCL chains from the matrix, induces a decline in the strength and elongation of composites. For example, the elongation at break decreased from $637 \%$ to $83 \%$ when $20 \mathrm{wt} \%$ of $\mathrm{PCL}_{10000}$-grafted starch nanocrystals was added.

\subsection{Reinforcement Mechanism of Starch Nanocrystal Filler.} It is well known that the structure and properties of nanocomposites are relevant to the cooperative effects of many factors including the various structures of matrices, the network among nanofillers and polymer matrices, the interfacial interactions, the scale of dispersion, morphology, and the surface functionality of the nanocrystals. A percolation mechanism, determined by three-dimensional networks formed by the interconnection of polysaccharide nanocrystals and stabilized by hydrogen bonding, is the predominant contributor to reinforcement of the resultant nanocomposites as it enhances tensile strength and Young's modulus gives a higher storage modulus, a thermally stable rubbery plateau, and affects the diffusion coefficient [24, 36, 45-48]. The percolation mechanism has been verified by successive tensile experiments, which consist of stretching the material to a given elongation, releasing the force, stretching again to a higher elongation, and repeating. It has been proven that over the percolation threshold $\left(\nu_{\mathrm{Rc}}\right)$, the polysaccharide nanocrystals connect and form a tridimensional continuous pathway through the nanocomposite [49]. The formation of this nanocrystal network results from strong interactions between crystals, such as hydrogen bonds [50], and improves the mechanical and thermal properties. This phenomenon is similar to the mechanical properties observed for a sheet of paper, which result from the hydrogen-bonding forces that hold the percolation network of fibers together [49]. The $v_{\mathrm{Rc}}$ is inversely proportional to the aspect ratio of nanofillers, such as, waxy maize starch nanocrystal-based nanocomposites-generally displayed improved mechanical properties at the filler content of about $5 \mathrm{wt} \%$ [24], which was due primarily to its lower aspect ratio and plateletlike geometry in contrast with rod-like cellulose whiskers. Any factor that affects the formation of the percolation nanocrystal network, or interferes with it, will change the performance of the composite [51]. There are three main parameters affecting the properties of such materials: the morphology and dimensions of the nanocrystals, the processing method, and the microstructure of the matrix and matrix-filler interactions [49]. It should be noted that although chemical reaction modification (ASA modified or PI modified) of starch nanocrystals improves the adhesion between the filler and matrix, it partially or totally destroys the three-dimensional network in the nanocomposites. This leads to a strong decrease in mechanical performance of the composites after chemical modification [24, 35]. Similar results have also been shown in the study of natural rubber nanocomposites reinforced with chemically modified crab shell chitin nanowhiskers [52].

The interfacial interactions among polysaccharide nanocrystals, grafted polymer chains, and the polymer matrix are another crucial factor affecting the structure and properties of composites [23, 25, 53]. Fast freezing during quenching before freeze-drying and high melting viscosity during compounding/molding inhibit the percolation mechanism in many polysaccharide nanocrystal-based nanocomposites. Furthermore, in some systems the percolation threshold is unachieved due to sedimentation of the filler or to low filler/matrix miscibility. In these cases, the interfacial interactions between filler and matrix participate in stress transfer to rigid nanometer sized fillers with higher stress endurance and become dominant in the reinforcement effect and in the simultaneous toughening effects. When starch nanocrystal was grafted from PCL chains and incorporated into PLA or WPU matrices, the entanglement and interaction between grafted polymer chains and polymer matrices facilitated the interfacial adhesion between the nanocrystals and matrices and hence contributed to the rigid nanocrystals endurance of higher stress. At the same time, the rubbery component of the grafted polymer chains, together with the formation of an interfacial layer, improved the elongation of the nanocomposites. The three-phase structure model shown in Figure 9 summarizes the interactions among the nanocrystals, the interfacial layer, and the polymer matrix. In addition, it should be pointed out that, using the same strategy, long and dense "plasticizing" tails of grafted polymer chains on polysaccharide nanocrystals entangle with each other and enable the modified nanocrystals to directly thermoform to make novel nanocomposites $[54,55]$.

\section{Conclusions and Outlook}

Starch nanocrystals, the nanoscale biofiller derived from native starch granules, have been compounded with many different kinds of polymer matrices. The intrinsic rigidity of starch nanocrystals, special platelet-like morphology, strong interfacial interactions, and the percolation network organized by nanocrystals all contribute to optimized 


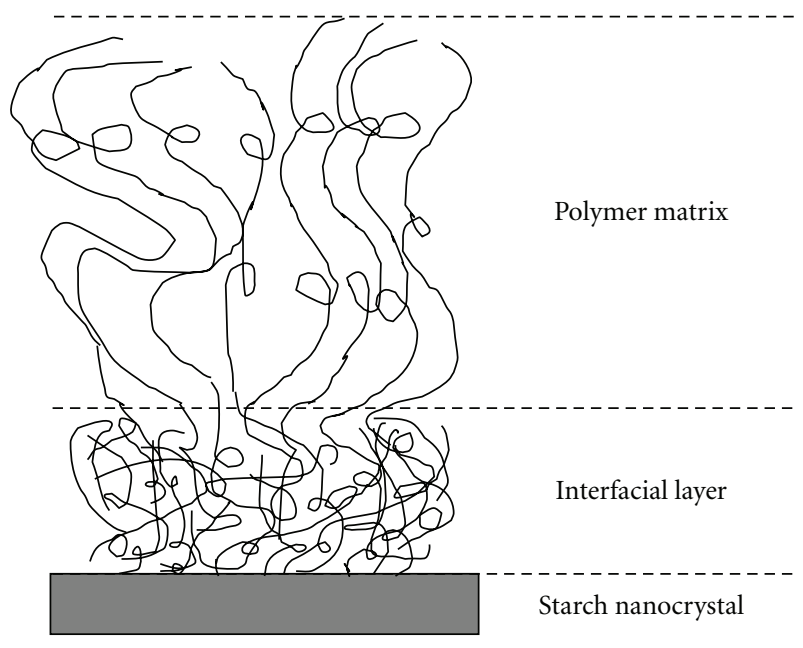

FIGURE 9: Schematic illustration of three-phase structure model.

mechanical performance, thermal properties, solvent absorption, and barrier properties. To improve interfacial adhesion between starch nanocrystals and polymer matrices, a series of chemical modifications based on "chemical reaction", "graft to," and "graft from" strategies have been carried out and, in some cases, markedly enhanced the performance of the nanomaterials. Some reinforcing mechanisms were proposed and used to manipulate the performance of starch nanocrystal-filled materials. Novel processing technology should be sought in order to accelerate the application of starch nanocrystals in nanomaterials. Lack of continuous processing technology makes current methods for production of nanomaterials reinforced with starch nanocrystals impractical. Furthermore, environmentally friendly processing and manufacturing must be developed in order to replace the current process which is energy intensive, requires strong/toxic chemicals, and is a burden on our fragile ecosystem and environment. In addition, cellulose nanocrystals have been introduced into the field of biomaterials, noticeably for use in bioimaging applications after fluorescent labeling modifications [56]. Compared to cellulose nanocrystals, the structure of starch nanocrystals is less durable, particularly during functional modification, which impairs the development for use of starch nanocrystals in the biomaterials field. Realization of functional modification of starch nanocrystals under mild reactive conditions would greatly improve its practical utility for the future.

\section{Acknowledgments}

The authors would like to express their gratitude to three anonymous reviewers and the Editor, Dr. Quanqin Dai, for their constructive comments and recommendations. The authors are also grateful to the Program of Energy Research and Development (PERD) of Natural Resources Canada, the Pulse Research Network (PURENet) through Agriculture, Agri-Food Canada's Agriculture Bioproducts Innovation Program (ABIP), National Natural Science
Foundation of China (50843031), 973 Projects of Chinese Ministry of Science and Technology (2007CB936104), Shanghai Municipality Commission for Special Project of Nanometer Science and Technology (0952nm05300), Shanghai Municipality Commission for International Corporation Project (10410710000) and for Non-Governmental International Corporation Project (09540709000), Fundamental Research Funds for the Central Universities (SelfDetermined and Innovative Research Funds of WUT 2010II-022), Youth Chenguang Program of Science \& Technology in Wuhan (200850731383), State Key Laboratory of Pulp and Paper Engineering, South China University of Technology (200906), and Key Laboratory of Cellulose and Lignocellulosics Chemistry, Guangzhou Institute of Chemistry, Chinese Academy of Sciences (LCLC-2010-10) for partial funding of this work.

\section{References}

[1] M. Paris, H. Bizot, J. Emery, J. Y. Buzaré, and A. Buléon, "Crystallinity and structuring role of water in native and recrystallized starches by 13C CP-MAS NMR spectroscopy. 1: spectral decomposition," Carbohydrate Polymers, vol. 39, no. 4, pp. 327-339, 1999.

[2] P. J. Jenkins, R. E. Comerson, A. M. Donald et al., "In situ simultaneous small and wide angle X-ray scattering: a new technique to study starch gelatinization," Journal of Polymer Science B, vol. 32, no. 8, pp. 1579-1583, 1994.

[3] T. A. Waigh, I. Hopkinson, A. M. Donald, M. F. Butler, F. Heidelbach, and C. Riekel, "Analysis of the native structure of starch granules with X-ray microfocus diffraction," Macromolecules, vol. 30, no. 13, pp. 3813-3820, 1997.

[4] T. A. Waigh, A. M. Donald, F. Heidelbach, C. Riekel, and M. J. Gidley, "Analysis of the native structure of starch granules with small angle X-ray microfocus scattering," Biopolymers, vol. 49, no. 1, pp. 91-105, 1999.

[5] T. Suzuki, A. Chiba, and T. Yano, "Interpretation of small angle X-ray scattering from starch on the basis of fractals," Carbohydrate Polymers, vol. 34, no. 4, pp. 357-363, 1998.

[6] M. J. Gidley and S. M. Bociek, "Molecular organization in starches: a 13C CP/MAS NMR study," Journal of the American Chemical Society, vol. 107, no. 24, pp. 7040-7044, 1985.

[7] S. Perez, P. Baldwin, and D. J. Gallant, "Structural features of starch granules I," in Starch: Chemistry and Technology, R. Whistler and J. BeMiller, Eds., pp. 149-192, Academic Press, New York, NY, USA, 3rd edition, 2009.

[8] P. J. Jenkins and A. M. Donald, "The influence of amylose on starch granule structure," International Journal of Biological Macromolecules, vol. 17, no. 6, pp. 315-321, 1995.

[9] J.-L. Putaux, A. Buléon, and H. Chanzy, "Network formation in dilute amylose and amylopectin studied by TEM," Macromolecules, vol. 33, no. 17, pp. 6416-6422, 2000.

[10] A. C. O'Sullivan and S. Perez, "The relationship between internal chain length of amylopectin and crystallinity in starch," Biopolymers, vol. 50, no. 4, pp. 381-390, 1999.

[11] A. Imberty, A. Buléon, V. Tran, and S. Péerez, "Recent advances in knowledge of starch structure," Starch-Stärke, vol. 43, no. 10, pp. 375-384, 1991.

[12] P. J. Jenkins and A. M. Donald, "The effect of acid hydrolyis on native starch granule structure," Starch-Stärke, vol. 49, no. 78, pp. 262-267, 1997. 
[13] Y.-J. Wang, V.-D. Truong, and L. Wang, "Structures and rheological properties of corn starch as affected by acid hydrolysis," Carbohydrate Polymers, vol. 52, no. 3, pp. 327-333, 2003.

[14] H. Angellier-Coussy, J.-L. Putaux, S. Molina-Boisseau, A. Dufresne, E. Bertoft, and S. Perez, "The molecular structure of waxy maize starch nanocrystals," Carbohydrate Research, vol. 344, no. 12, pp. 1558-1566, 2009.

[15] M. S. Buttrose, "Submicroscopic development and structure of starch granules in cereal endosperms," Journal of Ultrasructure Research, vol. 4, no. 3-4, pp. 231-257, 1960.

[16] T. A. Waigh, P. Perry, C. Riekel, M. J. Gidley, and A. M. Donald, "Chiral side-chain liquid-crystalline polymeric properties of starch,” Macromolecules, vol. 31, no. 22, pp. 7980-7984, 1998.

[17] L. Jayakody and R. Hoover, "The effect of lintnerization on cereal starch granules," Food Research International, vol. 35, no. 7, pp. 665-680, 2002.

[18] C. Gérard, P. Colonna, A. Buléon, and V. Planchot, "Order in maize mutant starches revealed by mild acid hydrolysis," Carbohydrate Polymers, vol. 48, no. 2, pp. 131-141, 2002.

[19] H. Zheng, F. Ai, P. R. Chang, J. Huang, and A. Dufresne, "Structure and properties of starch nanocrystal-reinforced soy protein plastics," Polymer Composites, vol. 30, no. 4, pp. 474480, 2009.

[20] G. Chen, M. Wei, J. Chen, J. Huang, A. Dufresne, and P. R. Chang, "Simultaneous reinforcing and toughening: new nanocomposites of waterborne polyurethane filled with low loading level of starch nanocrystals," Polymer, vol. 49, no. 7, pp. 1860-1870, 2008.

[21] J.-L. Putaux, S. Molina-Boisseau, T. Momaur, and A. Dufresne, "Platelet nanocrystals resulting from the disruption of waxy maize starch granules by acid hydrolysis," Biomacromolecules, vol. 4, no. 5, pp. 1198-1202, 2003.

[22] H. Angellier, L. Choisnard, S. Molina-Boisseau, P. Ozil, and A. Dufresne, "Optimization of the preparation of aqueous suspensions of waxy maize starch nanocrystals using a response surface methodology," Biomacromolecules, vol. 5, no. 4, pp. 1545-1551, 2004.

[23] P. R. Chang, F. Ai, Y. Chen, A. Dufresne, and J. Huang, "Effects of starch nanocrystal-graft-porycaprolactone on mechanical properties of waterborne polyurethane-based nanocomposites," Journal of Applied Polymer Science, vol. 111, no. 2, pp. 619-627, 2009.

[24] H. Angellier, S. Molina-Boisseau, and A. Dufresne, "Mechanical properties of waxy maize starch nanocrystal reinforced natural rubber," Macromolecules, vol. 38, no. 22, pp. 91619170, 2005.

[25] J. Yu, F. Ai, A. Dufresne, S. Gao, J. Huang, and P. R. Chang, "Structure and mechanical properties of poly(lactic acid) filled with (starch nanocrystal)-graft-poly(E-caprolactone)," Macromolecular Materials and Engineering, vol. 293, no. 9, pp. 763-770, 2008.

[26] H. Angellier, S. Molina-Boisseau, M. N. Belgacem, and A. Dufresne, "Surface chemical modification of waxy maize starch nanocrystals," Langmuir, vol. 21, no. 6, pp. 2425-2433, 2005.

[27] Y. Xu, W. Ding, J. Liu et al., "Preparation and characterization of organic-soluble acetylated starch nanocrystals," Carbohydrate Polymers, vol. 80, no. 4, pp. 1078-1084, 2010.

[28] W. Thielemans, M. N. Belgacem, and A. Dufresne, "Starch nanocrystals with large chain surface modifications," Langmuir, vol. 22, no. 10, pp. 4804-4810, 2006.
[29] M. Labet, W. Thielemans, and A. Dufresne, "Polymer grafting onto starch nanocrystals," Biomacromolecules, vol. 8, no. 9, pp. 2916-2927, 2007.

[30] H. Namazi and A. Dadkhah, "Convenient method for preparation of hydrophobically modified starch nanocrystals with using fatty acids," Carbohydrate Polymers, vol. 79, no. 3, pp. 731-737, 2010.

[31] M. N. Belgacem, J. Quillerou, and A. Gandini, "Urethanes and polyurethanes bearing furan moieties-3. Synthesis, characterization and comparative kinetics of the formation of diurethanes," European Polymer Journal, vol. 29, no. 9, pp. 1217-1224, 1993.

[32] H. Namazi and A. Dadkhah, "Surface modification of starch nanocrystals through ring-opening polymerization of $\varepsilon$-caprolactone and investigation of their microstructures," Journal of Applied Polymer Science, vol. 110, no. 4, pp. 24052412, 2008.

[33] S. Song, C. Wang, Z. Pan, and X. Wang, "Preparation and characterization of amphiphilic starch nanocrystals," Journal of Applied Polymer Science, vol. 107, no. 1, pp. 418-422, 2008.

[34] Y. Chen, X. Cao, P. R. Chang, and M. A. Huneault, "Comparative study on the films of poly(vinyl alcohol)/pea starch nanocrystals and poly(vinyl alcohol)/native pea starch," Carbohydrate Polymers, vol. 73, no. 1, pp. 8-17, 2008.

[35] H. Angellier, S. Molina-Boisseau, L. Lebrun, and A. Dufresne, "Processing and structural properties of waxy maize starch nanocrystals reinforced natural rubber," Macromolecules, vol. 38, no. 9, pp. 3783-3792, 2005.

[36] H. Angellier, S. Molina-Boisseau, and A. Dufresne, "Waxy maize starch nanocrystals as filler in natural rubber," Macromolecular Symposia, vol. 233, no. 1, pp. 132-136, 2006.

[37] T. Materne, F. Corvasce, and P. Leitz, European patent no. EP0995775A1, 2000.

[38] H. Angellier, S. Molina-Boisseau, P. Dole, and A. Dufresne, "Thermoplastic starch-waxy maize starch nanocrystals nanocomposites," Biomacromolecules, vol. 7, no. 2, pp. 531$539,2006$.

[39] J. Viguié, S. Molina-Boisseau, and A. Dufresne, "Processing and characterization of waxy maize starch films plasticized by sorbitol and reinforced with starch nanocrystals," Macromolecular Bioscience, vol. 7, no. 11, pp. 1206-1216, 2007.

[40] E. Kristo and C. G. Biliaderis, "Physical properties of starch nanocrystal-reinforced pullulan films," Carbohydrate Polymers, vol. 68, no. 1, pp. 146-158, 2007.

[41] H. Angellier, J.-L. Putaux, S. Molina-Boisseau, D. Dupeyre, and A. Dufresne, "Starch nanocrystal fillers in an acrylic polymer matrix," Macromolecular Symposia, vol. 221, no. 1, pp. 95-104, 2005.

[42] A. Dufresne, J. Cavaillé, and W. Helbert, "New nanocomposite materials: microcrystalline starch reinforced thermoplastic," Macromolecules, vol. 29, no. 23, pp. 7624-7626, 1996.

[43] Y. Wang and L. Zhang, "High-strength waterborne polyurethane reinforced with waxy maize starch nanocrystals," Journal of Nanoscience and Nanotechnology, vol. 8, no. 11, pp. 5831-5838, 2008.

[44] Y. Habibi and A. Dufresne, "Highly filled bionanocomposites from functionalized polysaccharide nanocrystals," Biomacromolecules, vol. 9, no. 7, pp. 1974-1980, 2008.

[45] K. G. Nair and A. Dufresne, "Crab shell chitin whisker reinforced natural rubber nanocomposites. 1. Processing and swelling behavior," Biomacromolecules, vol. 4, no. 3, pp. 657$665,2003$. 
[46] K. G. Nair and A. Dufresne, "Crab shell chitin whisker reinforced natural rubber nanocomposites. 2. Mechanical behavior," Biomacromolecules, vol. 4, no. 3, pp. 666-674, 2003.

[47] Y. Lu, L. Weng, and L. Zhang, "Morphology and properties of soy protein isolate thermoplastics reinforced with chitin whiskers," Biomacromolecules, vol. 5, no. 3, pp. 1046-1051, 2004.

[48] A. Dufresne and J.-Y. Cavaillé, "Clustering and percolation effects in microcrystalline starch-reinforced thermoplastic," Journal of Polymer Science B, vol. 36, no. 12, pp. 2211-2224, 1998.

[49] A. Dufresne, "Polysaccharide nanocrystal reinforced nanocomposites," Canadian Journal of Chemistry, vol. 86, no. 6, pp. 484-494, 2008.

[50] V. Favier, J. Y. Cavaillé, S. C. Shrivastava, and G. R. Canova, "Mechanical percolation in cellulose whisker nanocomposites," Polymer Engineering and Science, vol. 37, no. 10, pp. 1732-1739, 1997.

[51] A. Dufresne, "Comparing the mechanical properties of high performances polymer nanocomposites from biological sources," Journal of Nanoscience and Nanotechnology, vol. 6, no. 2, pp. 322-330, 2006.

[52] K. G. Nair, A. Dufresne, A. Gandini, and M. N. Belgacem, "Crab shell chitin whiskers reinforced natural rubber nanocomposites. 3. Effect of chemical modification of chitin whiskers," Biomacromolecules, vol. 4, no. 6, pp. 1835-1842, 2003.

[53] N. Lin, G. Chen, J. Huang, A. Dufresne, and P. R. Chang, "Effects of polymer-grafted natural nanocrystals on the structure and mechanical properties of poly(lactic acid): a case of cellulose whisker-graft-polycaprolactone," Journal of Applied Polymer Science, vol. 113, no. 5, pp. 3417-3425, 2009.

[54] G. Chen, A. Dufresne, J. Huang, and P. R. Chang, "A novel thermoformable bionanocomposite based on cellulose nanoerystal-graft-poly(E-caprolactone)," Macromolecular Materials and Engineering, vol. 294, no. 1, pp. 59-67, 2009.

[55] L. Feng, Z. Zhou, A. Dufresne, J. Huang, M. Wei, and L. An, "Structure and properties of new thermoforming bionanocomposites based ort chitin whisker-graftpolycaprolactone," Journal of Applied Polymer Science, vol. 112, no. 5, pp. 2830-2837, 2009.

[56] S. Dong and M. Roman, "Fluorescently labeled cellulose nanocrystals for bioimaging applications," Journal of the American Chemical Society, vol. 129, no. 45, pp. 13810-13811, 2007. 

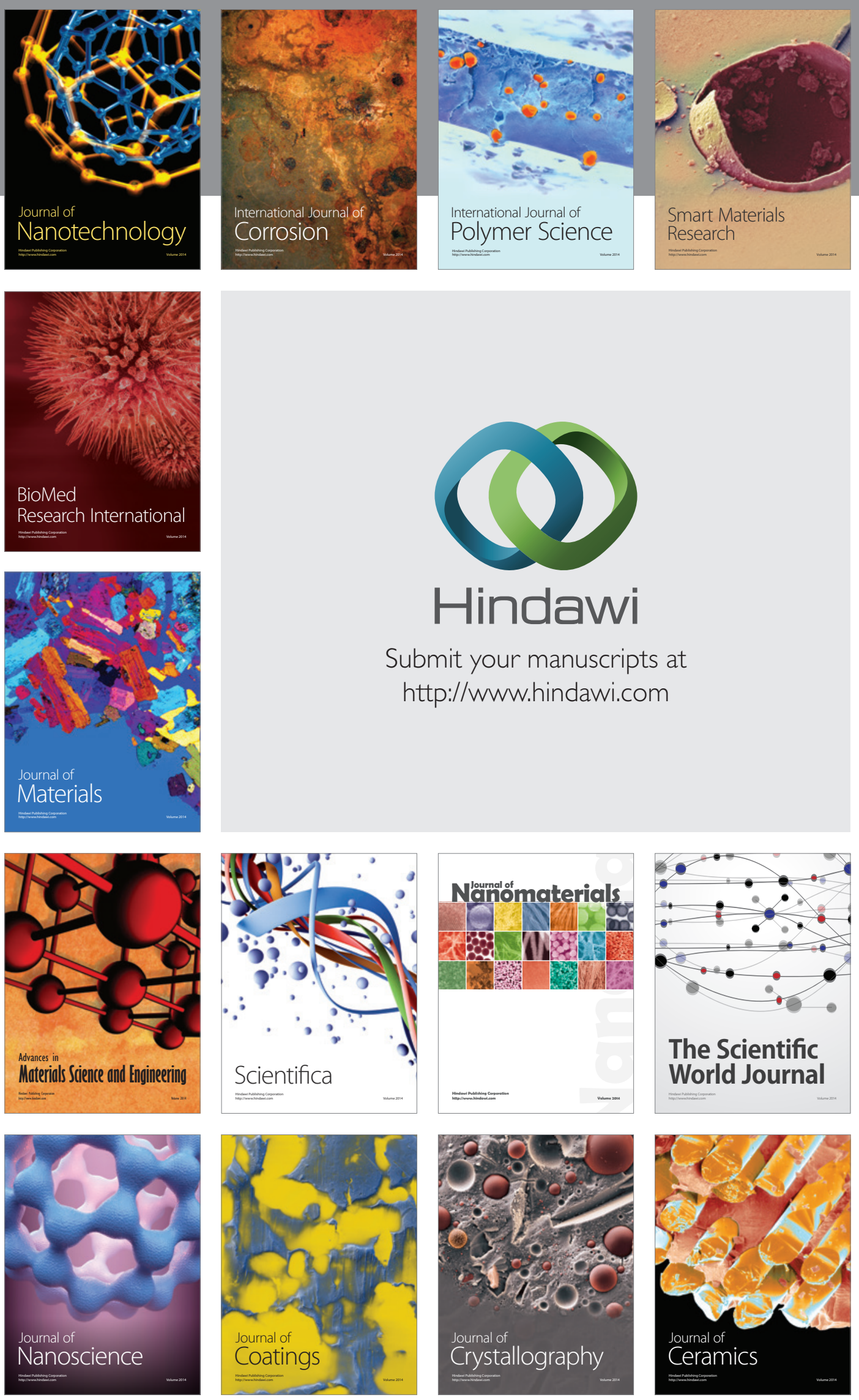

The Scientific World Journal

Submit your manuscripts at

http://www.hindawi.com

\section{World Journal}

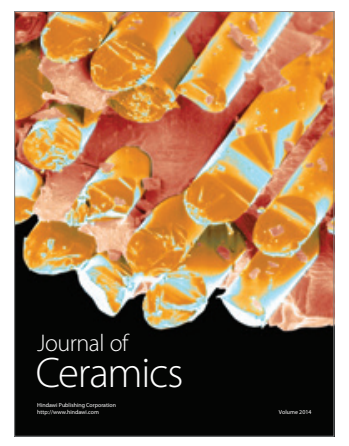

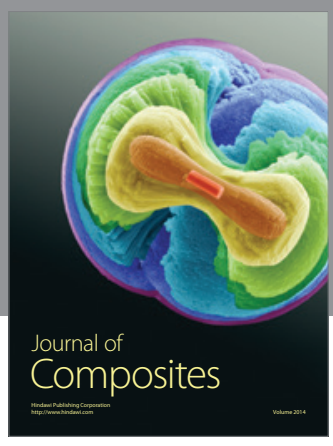
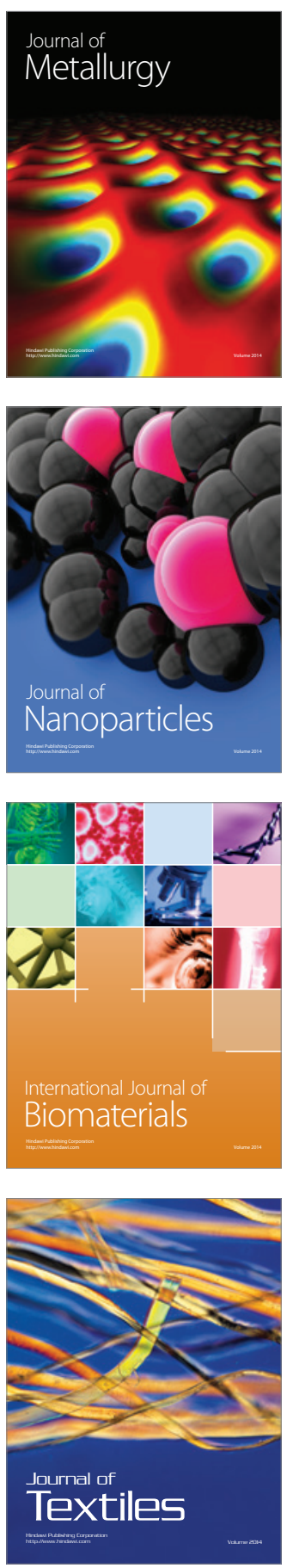